九州大学学術情報リポジトリ

Kyushu University Institutional Repository

\title{
FIVE NEW SPECIES OF TETRAGNATHA FROM ASIA (ARANEAE : TETRAGNATHIDAE)
}

Okuma, Chiyoko

https://doi.org/10.5109/2506

出版情報: ESAKIA. 26，pp.71-77，1988-01-25. Entomological Laboratory，Faculty of Agriculture， Kyushu University

バージョン :

権利関係 : 


\title{
FIVE NEW SPECIES OF TETRAGNATHA FROM ASIA (ARANEAE : TETRAGNATHIDAE)*
}

\author{
СНIYоко ОкUма \\ Entomological Laboratory, Faculty of Agriculture, \\ Kyushu University, Fukuoka 812, Japan
}

\begin{abstract}
Five new species of the spider genus Tetrugnatha Latreille, esakii, hiroshii, tanigawai, gressitti and josephi, are described from Asia.
\end{abstract}

In this paper, five new species of the genus Tetragnatha Latreille are described : esakii and hiroshii from Taiwan, tanigawai from Japan (Iriomote I.), gressitti from Borneo and josephi from Singapore. The first three species belong to the same species group, i. e., the squamata-group. The grouping of the species of Tetragnatha will be discussed in my separate paper (J. Fac. Agr., Kyushu Univ., 32 $(2 / 3)$, in press).

Before going further, I wish to express my hearty thanks to Prof. Y. Hirashima of Kyushu University for helpful suggestion and encouragement. I am also grateful to the following biologists for valuable specimens: Mr. Joseph Koh (Singapore), Mr. Hiroshi Makihara (Tsukuba), Mr. A. Tanigawa (Yokohama) and Dr. JoAnn M. Tenorio (Bishop Museum, Honolulu). I thank Assoc. Prof. K. Morimoto, Dr. 0. Tadauchi and Dr. K. Ogata of Kyushu University for their kindness in many ways.

\section{Tetragnatha esakii sp. nov.}

Male. Body length, exclusive of chelicerae $7.7-9.5 \mathrm{~mm}$; carapacial length $2.7-3.1 \mathrm{~mm}$, width 1.6-1.9 mm ; abdominal length 5.0-6.3 mm, width 1.3-1.7 mm ; cheliceral length 2.8-3.4 mm.

Eyes. Posterior row of eyes slightly narrower than anterior row of eyes $(95: 100)$; viewed from above, two rows nearly parallel and gently recurved; central ocular quadrangle nearly square ; ratio of diameter of AME : ALE:PME : PLE as $113: 75: 100: 100(\mu)$.

Chelicerae. Basal segment longer than carapace ; (a) slender, pointed at tip, (AXu) bluntly rounded at tip, slightly separated from $(\mathrm{Gu}) ;(\mathrm{Gu}),(\mathrm{U} 2)$ and (U3) subequal in size and spacing, (rsu) about 10 in number ; (AXl) absent, (Gl) very large, with two tubercles, (rsl) about 6 in number ; fang with a very long, forwardly curved outer cusp near base.

Legs. Leg formula 1.2.4.3 ; all legs with long spines, first femur with 7-10 spines.

Palpi. Paracymbium bluntly rounded at tip ; both conductor and embolus very long, tip of conductor hook-like, somewhat twisted as shown in Fig. 1, E and F.

* Contribution from the Entomological Laboratory, Faculty of Agriculture, Kyushu University, Fukuoka (Ser. 3, No. 252). 

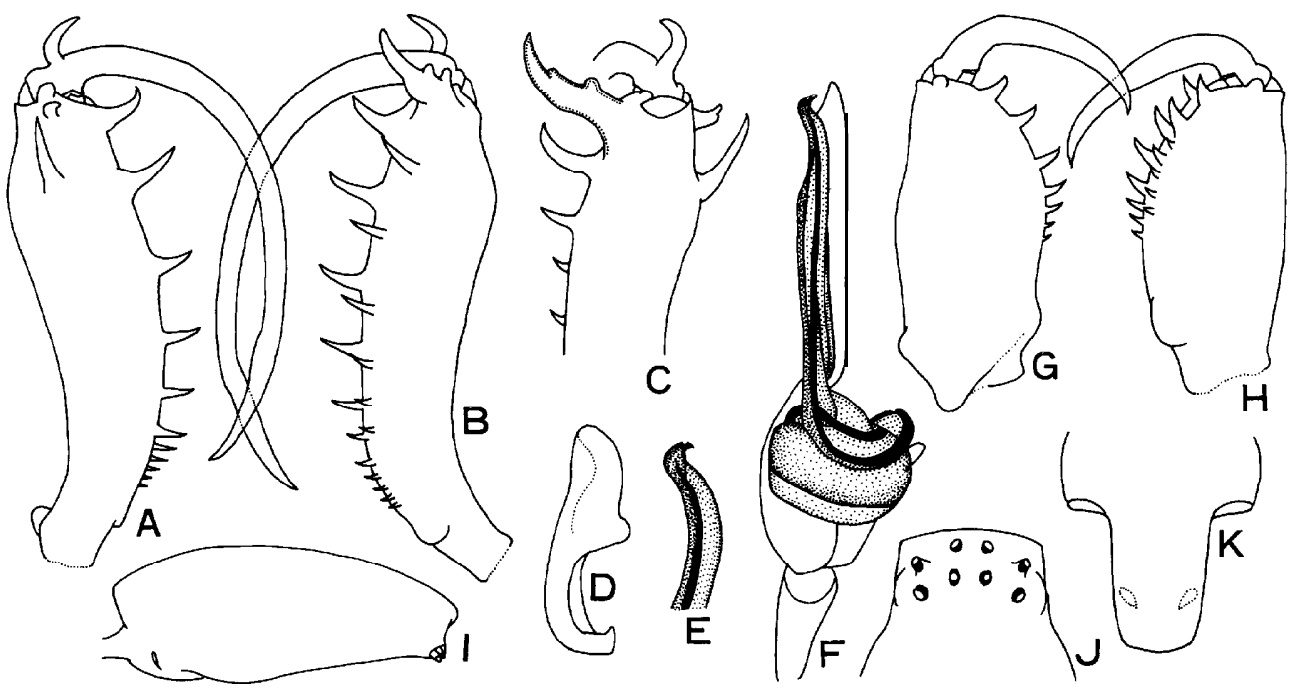

Fig. 1. Tetragnatha esakii sp. nov. A : Left chelicera of male, upper view. B : Ditto, lower view. C : Ditto, lateral view. D : Paracymbium of male. E : Distal portion of conductor and embolus of male. F : Left palpus of male. G : Left chelicera of female, upper view. H : Ditto, lower view. I : Abdomen of female, lateral view. J : Eye group of female. $\mathrm{K}$ : Genital fold of female.

Abdomen. Not so long, about 3.5-4.0 times as long as broad, distal end of abdomen somewhat overhanging spinnerets.

Color in alcohol. Generally whitish yellow ; abdomen covered with many silvery spangles.

Female. Body length, exclusive of chelicerae 7.4-9.3 mm ; carapacial length $2.6-2.7 \mathrm{~mm}$, width 1.6-1.7 mm ; abdominal length 4.8-6.6 mm, width $1.8-3.0 \mathrm{~mm}$; cheliceral length $1.3-1.4 \mathrm{~mm}$.

Eyes. Nearly as in male.

Chelicerae. Basal segment about one-half of carapace, without particular features.

Legs. Leg formula 1.2.4.3 ; all legs with long spines, first femur with 6-7 spines.

Abdomen. Not so long, less than 3 times as long as broad, somewhat swollen at the middle.

Color in alcohol. Similar to male.

TyPE MATERIAL : Holotype ơ (Type No. 2637, Kyushu Univ.) Loloshan, Taoyuan Hsien, Taiwan, 24. V. 1980, H. Makihara. Paratopotypes : 30, 2\%, same data as holotype.

DisTRIBUTION : Taiwan.

Note: This species is very similar to T. yesoensis Saito in many respects, but it is separable from the latter in the arrangement of cheliceral teeth in the male (the space between (Gu) and (U2) is very long in yesoensis, and short in the new species). The shapes of the male conductor and the male (EX) are also different from those of yesoensis.

This species is named in honor of my teacher, the late Prof. Teiso Esaki.

\section{Tetragnatha hiroshii sp. nov.}

Male. Carapacial length $1.9 \mathrm{~mm}$, width $1.3 \mathrm{~mm}$; chekiceral length $1.9 \mathrm{~mm}$ (abdomen lost).

Eyes. Anterior row and posterior row of eyes about equal in width ; viewed from above, two rows nearly parallel and recurved; central ocular quadrangle with posterior ocular width slightly 


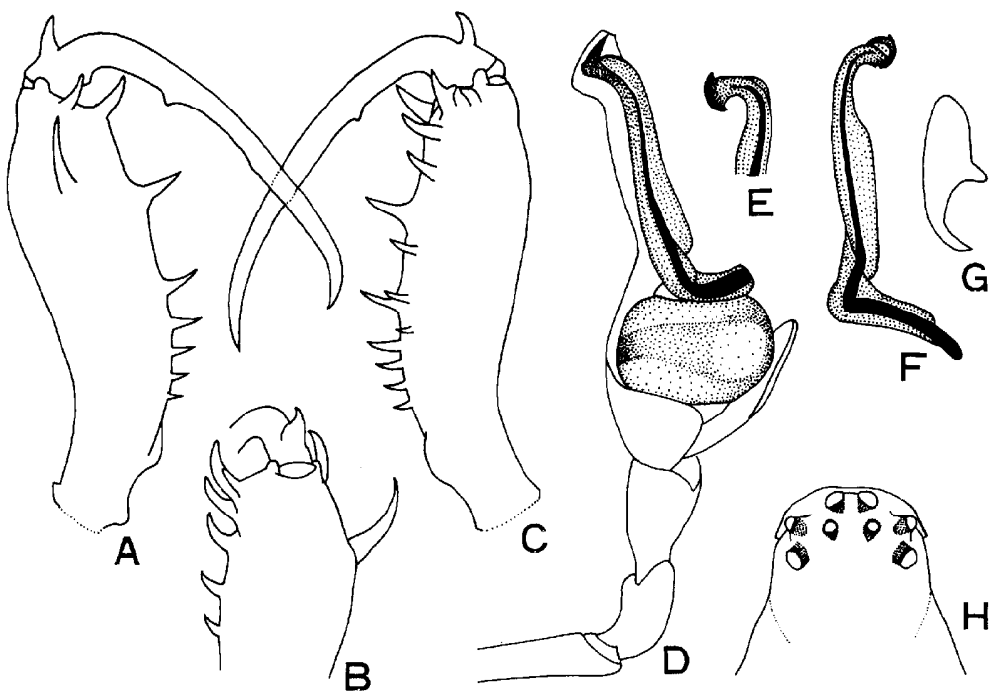

Fig. 2. Tetragnatha hiroshii sp. nov. A : Left chelicera of male, upper view. B : Ditto, lateral view. C : Ditto, lower view. D : Left palpus of male. $\mathrm{E}$ and F: Conductor and embolus of male. G : Paracymbium of male. $\mathrm{H}$ : Eye group of male.

larger than anterior ocular width $(113: 100)$, and slightly larger than antero-posterior ocular length (120: 100); ratio of diameter of AME : ALE : PME : PLE as $100: 75: 75: 75(\mu)$.

Chelicerae. Basal segment about as long as carapace ; (a) slender and pointed at tip ; $(\mathrm{AXu})$ long and pointed at tip, (Gu), (U2) an4 (U3) subequal in size and spacing; (AXl) present, close to (Gl), bluntly rounded at tip, (Gl) large, with a tubercle at the middle, (L2) close to (Gl), (rsl) 5 in number ; fang with an outer cusp near base, and an inner cusp at about $1 / 3$ from base.

Legs. Leg formula 1.2.4.3 ; all legs with spines, first femur with 4 spines.

Palpi. Paracymbium bluntly rounded at tip ; distal end of conductor hook-like and distinctly recurved and twisted as shown in Fig. 2, D, E and F.

Color in alcohol. Generally yellowish brown.

TYPE MATERIAL : Holotype ơ (Type No. 2638, Kyushu Univ.) Loloshan, Taoyuan Hsien, Taiwan, 21. V. 1980, H. Makihara.

DistRIBUTION : Taiwan.

Note : This species is very similar to T. squamata Karsch, 1879 and T. tunigawai sp. nov. in many respects, but it is easily separable from them by having an inner cusp on the cheliceral fang in the male. The shape of the male conductor is also different from those of squamata and tanigawai.

This species is named after Mr. Hiroshi Makihara, an entomologist in Tsukuba.

\section{Tetragnatha tanigawai sp. nov.}

Male. Body length, exclusive of chelicerae 4.8-5.1 mm; carapacial length $1.7 \mathrm{~mm}$, width $1.0^{-}$ $1.1 \mathrm{~mm}$; abdominal length 3.1-3.4 mm, width 0.85-0.9 mm ; cheliceral length 1.2-1.4 mm.

Eyes. Posterior row of eyes slightly narrower than anterior row of eyes $(95: 100)$; viewed from above, two rows nearly parallel and gently recurved ; central ocular quadrangle nearly square ; ratio of diameter of AME: ALE : PME : PLE as $100: 70: 70: 80(\mu)$. 


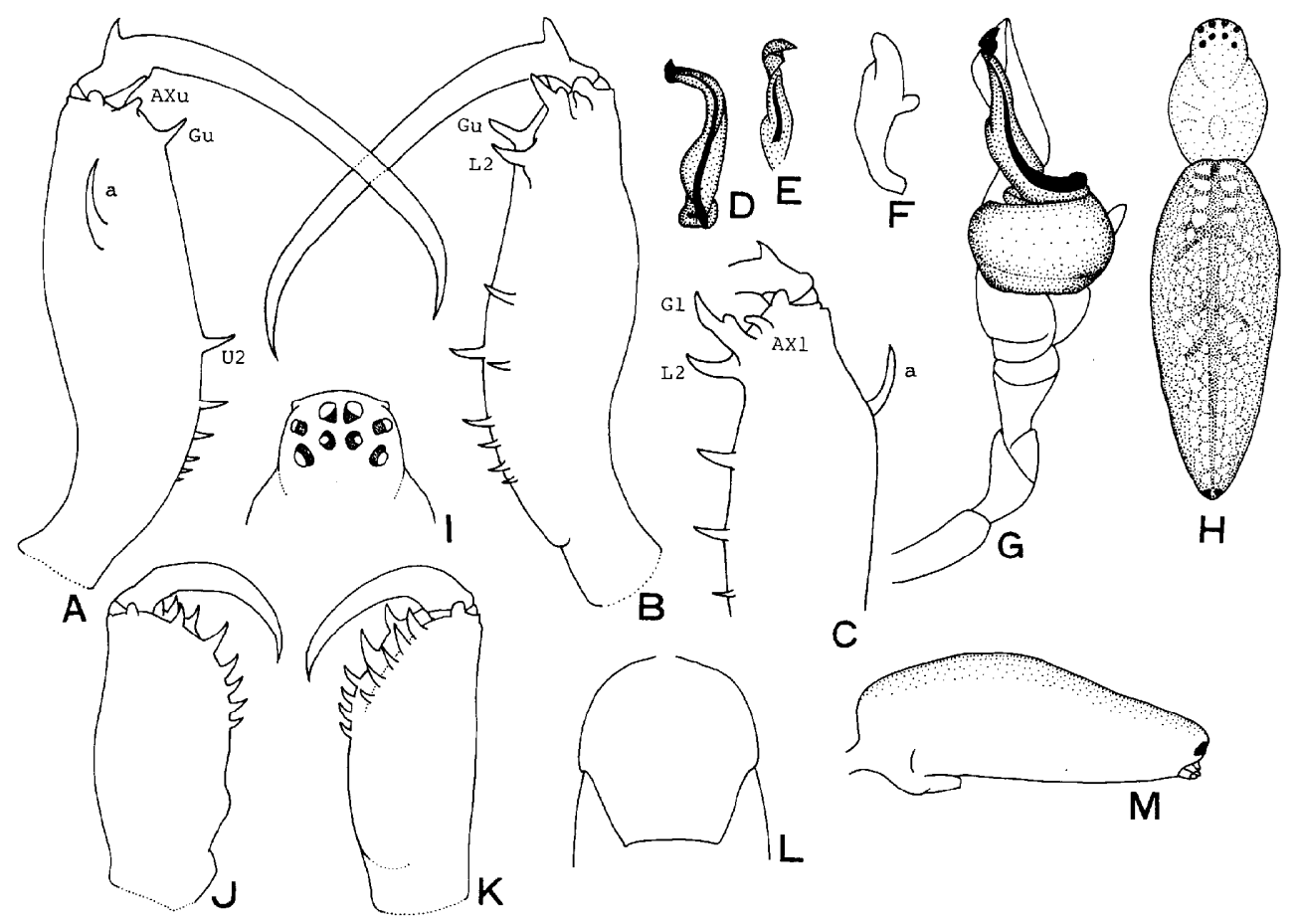

Fig. 3. Tetragnatha tanigawai sp. nov. A: Left chelicera of male, upper view. B : Ditto, lower view. $\mathrm{C}$ : Ditto, lateral view. D and E : Conductor and embolus of male. F : Paracymbium of male. G : Left palpus of male. H : Female. I : Eye group of female. J : Left chelicera of female, upper view. $\mathrm{K}$ : Ditto, lower view'. L : Genital fold of female. $\mathrm{M}$ : Abdomen of female, lateral view.

Chelicerae. Basal segment about $4 / 5$ as long as carapace ; (a) slender, pointed at tip ; $(\mathrm{AXu})$ bluntly rounded at tip, (U2) widely separated from (Gu), (rsu) 4 in number ; $(\mathrm{AXl})$ present, close to $(\mathrm{Gl})$, (Gl) large, with a tubercle at the middle, (rsl) 3-4 in number ; fang with an outer cusp near base.

Legs. Leg formula 1.2.4.3 ; all legs with spines, first femur with 2-3 spines.

Palpi. Paracymbium bluntly rounded at tip ; conductor somewhat broad at the middle, and hooklike at tip as shown in Fig. 3, D, E and G.

Abdomen. Not so long, less than 3 times as long as broad, distal end of abdomen somewhat overhanging spinnerets.

Color in alcohol. Generally whitish yellow ; distal end of each segment of legs somewhat blackish ; abdomen covered with many silvery spangles, somewhat dark yellow dorsally, a pair of small blackish markings present near spinnerets.

Female. Body length, exclusive of chelicerae 5.2-5.8 mm ; carapacial length 1.7-1.9 mm, width 1.0-1.2 mm ; abdominal length 3.8-4.1 mm, width 1.3-1.6 mm ; cheliceral length 0.7-0.8 mm.

Eyes. Nearly as in male.

Chelicerae. Basal segment slightly shorter than one-half of carapace, without particular features. Legs. Nearly as in male.

Abdomen. Not so long, relatively shorter than in male, somewhat swollen at the middle.

Color in alchohol. Similar to male. 
TyPe Material : Holotype ơ (Type No. 2639, Kyushu Univ.) Iriomote I., Ryukyus, Japan, 1. IV. 1985, A. Tanigawa. Paratopotypes: $10^{7}, 49$, same data as holotype.

DistRIBUTION ; Iriomote I. of the Ryukyus, Japan.

Note: This species is very similar to $T$. squamata Karsch in many respects, but it is easily separable from the latter in having a pair of small blackish markings near the spinnerets in both sexes. In addition, the number of spines on legs different from the latter (first femur with 2-3 spines in tanigawai, whereas that of squamata with 6-7 spines), and the arrangement of cheliceral teeth in the male also somewhat different from that of the latter.

This species is named after Mr. A. Tanigawa of Yokohama.

\section{Tetragnatha gressitti sp. nov.}

M ale. Body length, exclusive of chelicerae 5.5-6.0 mm ; carapacial length 1.4-1.5 mm, width 0.6 $\mathrm{mm}$; abdominal length 4.1-4.6 mm, width $0.5 \mathrm{~mm}$; cheliceral length $0.7-0.8 \mathrm{~mm}$.

Eyes. Anterior row of eyes occupying full width of head, posterior row of eyes about as wide as anterior one ; viewed from above anterior row somewhat strongly recurved, posterior row moderately recurved, so that lateral eyes slightly closer than median eyes ; central ocular quadrangle nearly square ; ratio of diameter of AME : ALE : PME : PLE as $100: 45: 88: 70(\mu)$.

Chelicerae. Basal segment about one-half of carapace ; (a) not bifurcated at tip ; (sl) directed forward, (T) considerably long, (rsu) 3-4 in number ;(Gl) small, (rsl) 3 in number ; fang unarmed.

Legs. Leg formula 1.4.2.3 ; all legs without spines.

Palpi. Paracymbium slender, curved, and somewhat pointed at tip; conductor and embolus unique as shown in Fig. 4, D and E.

Abdomen. Very long, about 9 times as long as broad, not extended posteriorly to spinnerets.

Color in alcohol. Generally pale brown, with only blackish markings near spinnerets.

Female. Unknown.

HolotyPE : $\sigma^{\top}$ (BISHOP 13923), Borneo, Sandakan Bay (SW), Sapagaya Lumber Camp 2-20 m, 7.

XI. 1957, J. L. Gressitt. Paratype :10 , same data as holotype.

TYPE DEPository : Bishop Museum.

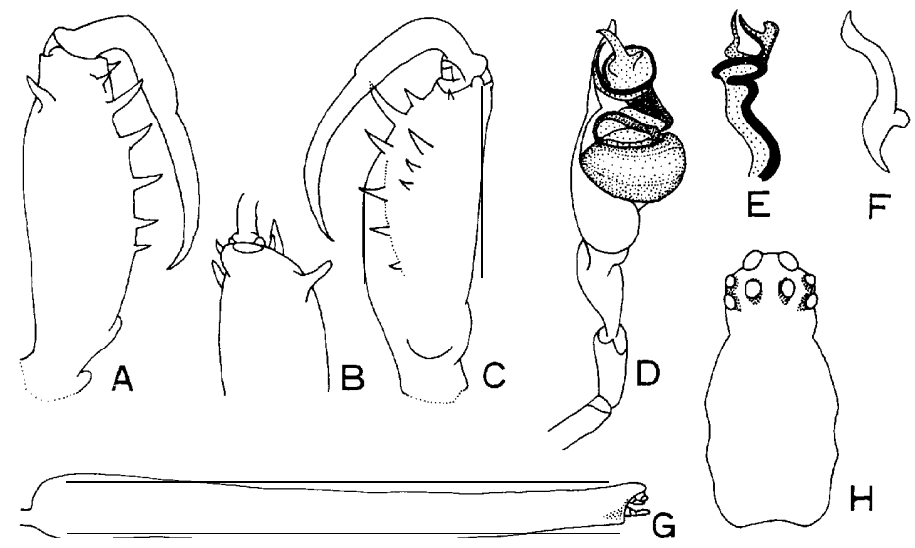

Fig. 4. Tetragnatha gressitti sp. nov. A: Left chelicera of male, upper view. B : Ditto, lateral view. C : Ditto, lower inner view. D : Left palpus of male. E: Conductor and embolus of male. F: Paracymbium of male. G : Abdomen of male, lateral view. H: Carapace of male, upper view. 
DistRIBUTION : Borneo,

Note: This new species is related to T. biseriata Thorell from New Guinea, Aru I. and Australia, but it may be easily distinguished from the latter by the characteristic male palpal conductor and paracymbium as shown in Fig. 4, D and E.

This species is named in honor of the late Dr. J. L. Gressitt. Bishop Museum (Honolulu) and Wau Ecology Institute (Papua New Guinea), to whom I am grateful for his kind assistance in many ways.

\section{Tetragnatha josephi sp. nov.}

Male. Body length, exclusive of chelicerae 5.5-5.8 mm ; carapacial length 1.9-2.0 mm, width 1.2 $\mathrm{mm}$; abdominal length 3.6-3.8 mm, width $0.9 \mathrm{~mm}$; cheliceral length $2.5 \mathrm{~mm}$.

Eyes. Anterior row of eyes occupying full width of head, posterior row about as wide as anterior one ; viewed from above, two rows nearly parallel and moderately recurved; lateral eyes slightly more separated than median eyes ; central ocular quadrangle nearly square ; ratio of diameter of AME : ALE: PME : PLE as $125: 88: 100: 100(\mu)$.

Chelicerae. Long, slender, basal segment about 1.2 times as long as carapace ; (a) large, bifurcated at tip ; (a), (t) and (sl) forming a group of three teeth ; conspicuous long (T) present at about $3 / 5$ from base, (rsu) 6- 8 in number ; (Gl) somewhat robust, (rsl) 6-7 in number, and arranged discontinuously ; fang long, slender, unarmed.

Legs. Leg formula 1.2.4.3 ; all legs with sparse, somewhat long spines, first femur with 5-7 spines.

Palpi. Paracymbium broad at the middle and pointed at tip ; conductor somewhat twisted.

Abdomen. Moderately long, about 4 times as long as broad, not extended posteriorly to spinnerets.

Color in alcohol. Legs, carapace, sternum and mouth parts generally yellowish brown ; legs with dusky rings near distal parts of each segment ; carapace darkened medially and laterally ; abdomen generally pale grayish brown. and with indistinct dusky markings and covered with sparse dusky silvery spangles dorsally, with a central dark gray strip ventrally.

Female. Body length, exclusive of chelicerae 6.6-9.7 mm ; carapacial length 2.1-2.7 mm, width 1.3-1.7 mm ; abdominal length 4.5-6.9 mm, width 1.3-1.8 mm ; cheliceral length 1.7-2.4 mm.

Eyes. Nearly as in male.

Chelicerae. Basal segment, about 0.8-0.9 times as long as carapace ; $(\mathrm{Gu})$ somewhat robust, (U3) widely senarated from (U2), (rsu) 7-9 in number ;(Gl) somewhat robust and slightly curved, (rsl) 6-9 in mumber ; fang with (EX) near base.

Legs. Leg formula 1.4.2.3 ; all legs with sparse, somewhat long spines, first femur with 5-7 spines.

Abdomen. Moderately long, more than 3 times as long as broad, not extended posteriorly to spinnerets ; genital fold as shown in Fig. 5, I.

Color in alcohol. Similar to male but abdomen with more conspicuous markings as usual for the genus.

HolotyPE : $\sigma^{7}$ (Type No. 2640, Kyushu Univ.), Singapore, Kampong Irau, swamp tree, 17. III. 1985, Joseph Koh. Paratypes: 19, Singapore, Krarji, mangrove swamp, 17. XII. 1976 ; 16 and ‘ 19, same data as holotype ; all specimens were collected by Mr. Joseph Koh.

DistRIBUTION : Singapore.

NotE: The upper distal portion of the male chelicera is similar to T.nitens (Audouin) for the arrangement of three strong teeth, but the new species is easily separable from nitens by having the large and long (T) on the upper margin of fang groove. It is also strikingly different from the congeneric species of Tetragnatha by the shape of the male palpal paracymbium and conductor.

This species is named after Mr. Joseph Koh of Singapore. 


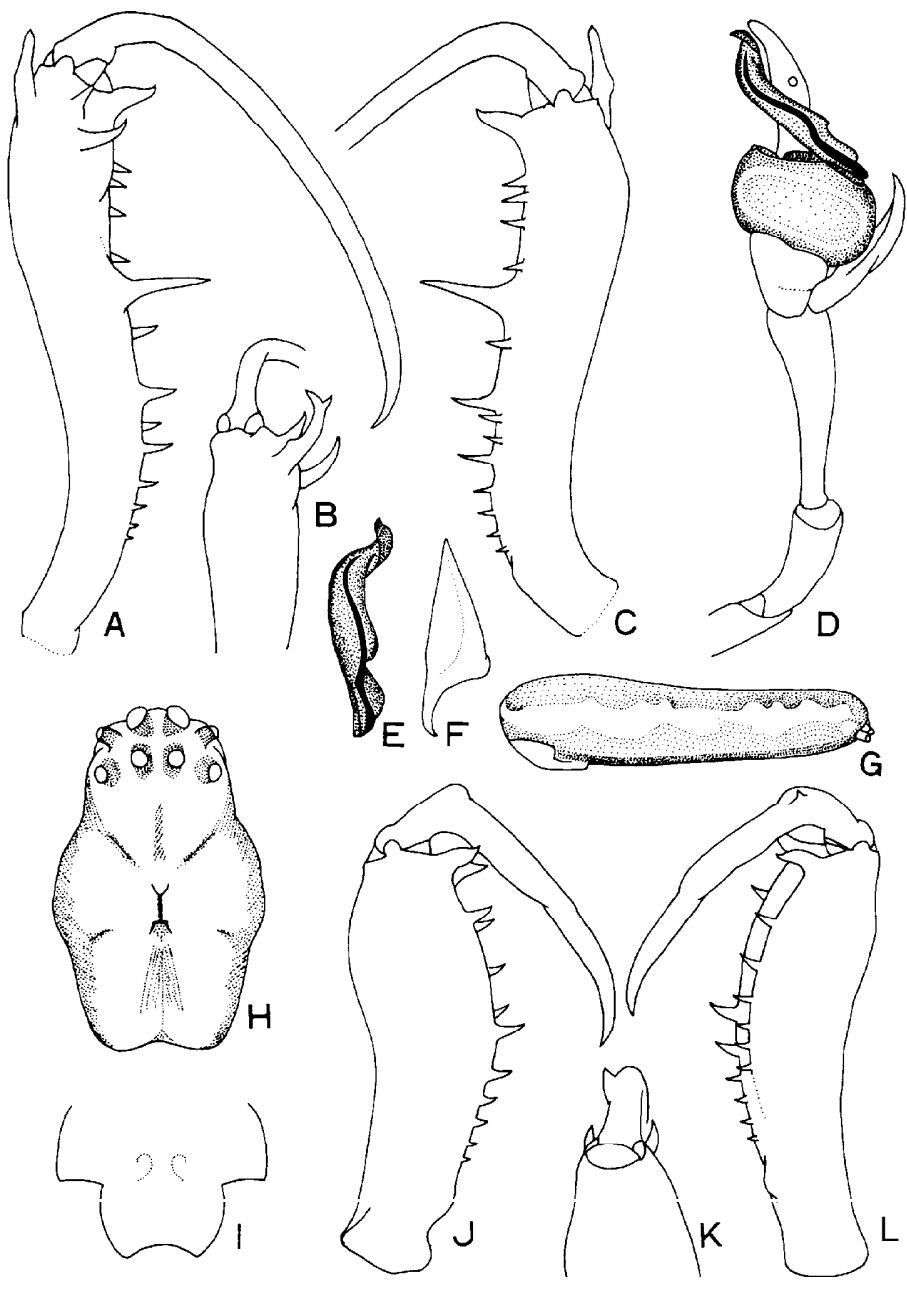

Fig. 5. Tetragnathu josephi sp. nov. A : Left chelicera of male, upper view. B : Ditto, lateral view. C : Ditto, lower view. D : Left palpus of male. E : Conductor and embolus of male. F : Paracymbium of male. G : Abdomen of female, lateral view. $\mathrm{H}$ : Carapace of male, upper view. I : Genital fold of female. J : Left chelicera of female, upper view. $\mathrm{K}:$ Ditto, lateral view. L : Ditto, lower view. 